\section{(2) OPEN ACCESS}

\title{
Conjunctival melanoma treatment outcomes in 288 patients: a multicentre international data-sharing study
}

\author{
Puneet Jain, ${ }^{1}$ Paul T Finger (1), ${ }^{1}$ Maria Fili, ${ }^{2}$ Bertil Damato, ${ }^{3}$ Sarah E Coupland ${ }^{4}$ \\ Heinrich Heimann, ${ }^{4}$ Nihal Kenawy, ${ }^{5}$ Niels I Brouwer, ${ }^{6}$ Marina Marinkovic, ${ }^{6}$ \\ Sjoerd G Van Duinen, ${ }^{6}$ Jean Pierre Caujolle, ${ }^{7}$ Celia Maschi, ${ }^{7}$ Stefan Seregard, ${ }^{2}$ \\ David Pelayes, ${ }^{8}$ Martin Folgar, ${ }^{8}$ Yacoub A Yousef, ${ }^{9}$ Hatem Krema, ${ }^{10}$ Brenda Gallie, ${ }^{10}$ \\ Alberto Calle-Vasquez, ${ }^{11}$ American Joint Committee on Cancer Ophthalmic Oncology \\ Task Force
}

\begin{abstract}
${ }^{1}$ The New York Eye Cancer Center, New York, New York, USA

${ }^{2}$ St. Er's Eye Hospital, Karolinska Institute, Stockholm, Sweden ${ }^{3}$ University of Oxford, Oxford, England

${ }^{4}$ Royal Liverpool University Hospital, Liverpool, England

${ }^{5}$ Liverpool University Hospitals NHS Foundation Trust,

Liverpool, England

${ }^{6}$ Leiden University Medical

Center, Leiden, Netherlands

${ }^{7}$ St. Roch Hospital, Nice

University Hospital, Nice, France

${ }^{8}$ Carlos G Durand Hospital,

Buenos Aires, Argentina

${ }^{9}$ King Hussein Cancer Center,

Amman, Jordan

${ }^{10}$ Princess Margaret Hospital, Toronto, Ontario, Canada

${ }^{11}$ Calle Ophthalmic and Orbit

Center, Bogota D.C., Colombia
\end{abstract}

\section{Correspondence to}

Paul T Finger, The New York

Eye Cancer Center, Suite 5A/B

115 East, 61st Street,

New York, NY 10065, USA;

pfinger@eyecancer.com

Received 12 March 2020

Revised 26 June 2020

Accepted 9 August 2020
Check for updates

(C) Author(s) (or their employer(s)) 2020. Re-use permitted under CC BY-NC. No commercial re-use. See rights and permissions. Published by BMJ.

To cite: Jain $\mathrm{P}$, Finger $\mathrm{PT}$, Fili M, et al. Br J Ophthalmol Epub ahead of print: [please include Day Month Year]. doi:10.1136/bjophthalmol2020-316293

\section{ABSTRACT}

Background To relate conjunctival melanoma characteristics to local control.

Methods Retrospective, registry-based interventional study with data gathered from 10 ophthalmic oncology centres from 9 countries on 4 continents. Conjunctival melanoma patients diagnosed between January 2001 and December 2013 were enrolled in the study. Primary treatments included local excision, excision with cryotherapy and exenteration. Adjuvant treatments included topical chemotherapy, brachytherapy, proton and external beam radiotherapy (EBRT). Cumulative 5-year and 10-year Kaplan-Meier local recurrence rates were related to clinical and pathological T-categories of the eighth edition of the American Joint Committee on Cancer (AJCC) staging system.

Results 288 patients had a mean initial age of 59.7 \pm 16.8 years. Clinical T-categories (cT) were $\mathrm{cT} 1$ $(n=218,75.7 \%)$, cT2 $(n=34,11.8 \%)$, cT3 $(n=15$, $5.2 \%)$, cTx ( $n=21,7.3 \%)$ with no cT4. Primary treatment included local excision ( $n=161 / 288,55.9 \%)$ followed by excision biopsy with cryotherapy $(n=108 /$ $288,37.5 \%)$ and exenteration $(n=5 / 288,1.7 \%)$. Adjuvant therapies included topical mitomycin $(n=107 /$ $288,37.1 \%)$, plaque-brachytherapy $(n=55 / 288$, $19.1 \%)$, proton-beam $(n=36 / 288,13.5 \%)$, topical interferon $(n=20 / 288,6.9 \%)$ and EBRT $(n=15 / 288$, $5.2 \%$ ). Secondary exenteration was performed $(n=11 /$ $283,3.9 \%$ ). Local recurrence was noted in $19.1 \%$ (median=3.6 years). Cumulative local recurrence was $5.4 \%(3.2-8.9 \%), 19.3 \%(14.4-25.5 \%)$ and $36.9 \%$ $(26.5-49.9 \%)$ at 1,5 and 10 years, respectively. CT3 and CT2 tumors were twice as likely to recur than CT1 tumours, but only CT3 had statistically significantly greater risk of local recurrence than T1 $(p=0.013)$. Factors such as tumour ulceration, plica or caruncle involvement and tumour thickness were not significantly associated with an increased risk of local recurrence.

Conclusion This multicentre international study showed that eighth edition of AJCC tumour staging was related to the risk of local recurrence of conjunctival melanoma after treatment. The 10-year cumulative local recurrence remains high despite current management.

\section{INTRODUCTION}

Conjunctival melanoma is rare, comprising $<1 \%$ of all (whole body) melanomas. ${ }^{12}$ The incidence is less than 1 case per million population, but it is on the rise. $^{2-4}$ Tumour staging is widely performed according to the eighth edition of the American Joint Committee on Cancer (AJCC) staging system. ${ }^{5} 6$

The most common treatment is wide excision with cryotherapy. ${ }^{2} 4$ Over the last several decades, topical chemotherapy and/or radiotherapy have been applied both as primary therapy and adjuvant therapy. ${ }^{4-10}$ Despite close surveillance and intensive therapy at subspeciality centres, the 10 -year tumour recurrence rates are reported to be as high as $69 \% .^{211-16}$ Reported risk factors for local recurrence include non-bulbar tumour location, higher AJCC stage, increased tumour thickness and ulceration. ${ }^{11-16}$

The last decade has seen a significant growth towards eye cancer research collaboration. Multicentre studies able to accumulate large cohorts of patients with rare eye tumours, amenable to statistically significant analysis in terms of clinical spectrum, management and treatment outcomes include: uveal melanoma, ocular adnexal lymphoma, iris melanoma, eyelid lymphoma to name a few. ${ }^{17-25}$ These efforts have improved, evidence-based understanding of the natural history of the tumours and standards of patient care. Moreover, collaborative data sharing also help in refining and validating the tumour staging systems. 526

Herein, we present the first multicentre, international, registry-based study of tumour characteristics and control as well as the cumulative 5 -year and 10 -year local recurrence rates in patients with conjunctival melanoma. This database has been used to validate/assess the eighth edition of the AJCC staging manual for conjunctival melanoma. ${ }^{5}$

\section{METHODS}

\section{Conjunctival melanoma registry}

The AJCC Ophthalmic Oncology Task Force created and used an internet-based registry to share data from 10 ophthalmic oncology centres in nine countries from four continents. ${ }^{5}$ This study 
conformed to the tenets of the Declaration of Helsinki and the United States of America Health Insurance Portability and Accountability Act of 1996. Internal Review Board approvals were obtained by each of the participating centres for retrospective chart review, data-pooling, analysis and publication.

\section{Patient enrolment}

This multicentre international study included patients diagnosed with conjunctival melanoma between 1 January 2001 and 31 December 2013. Open enrolment of subspeciality centres occurred during The First Eye Cancer Working Day held at the Curie Institute, Paris, France, in 2015. ${ }^{27}$

\section{Data collection and security}

Data collection was retrospective. Each of the participating centres had separate user accounts (distinct usernames with passwords) ensuring limited registry access. The digital representation of the patients was by means of unique identification numbers; therefore, no personal patient identifiers existed. Secure socket layer encryption and record locking ensured data sanctity. ${ }^{5}$

\section{Ophthalmic examination}

Demographic data included patient age and sex. Ophthalmic examinations were inclusive of, but not limited to slit-lamp biomicroscopy with photography, gonioscopic photography, dilated fundus examination and high-frequency anterior segment ultrasound imaging to rule out intra-ocular invasion. Orbital imaging in the form of either CT or MRI was performed. All the participating centres performed the examinations as per their usual standards and practices.

\section{Regional and systemic examination}

Regional examination was limited to clinical assessment of the pre-auricular, post-auricular, submandibular and anterior cervical lymph nodes. Systemic examination used radiographic imaging including CT, MRI and whole-body positron emission tomography/computed tomography (PET/CT). ${ }^{28} 29$

\section{Tumour staging}

Tumour staging was performed according to the eighth edition of the AJCC staging system for conjunctival melanoma, as shown in table 1 .

\section{Treatment}

Local treatments represented the standards of care at each subspeciality ophthalmic oncology centre. The primary treatment included, but was not limited to, wide local excision, excision biopsy with cryotherapy, enucleation, exenteration. Alternative or adjuvant treatment included topical chemotherapy, plaque brachytherapy, proton beam therapy and external beam radiotherapy (EBRT). Topical chemotherapeutic agents included mitomycin-C (MMC, $0.02 \%$ or $0.04 \%$ ), topical interferon-alfa $2 \mathrm{~b}$ (IFN $\alpha 2 \mathrm{~b}, 1$ million IU/ $\mathrm{mL}$ ) and 5-fluorouracil (5-FU, 1\%). Plaque brachytherapy was with either with ruthenium-106 or strontium-90 plaques.

\section{Local tumour recurrence}

Recurrence was defined by each clinical centre. The data field entry was 'local recurrence', and details were recorded as type, date and site of recurrence.

\section{Statistical analysis}

Continuous variables were expressed as mean with SD or median with IQR, and group-wise comparisons were made using the Student's t-test for parametric variables or
Wilcoxon rank-sum test for non-parametric variables. Categorical variables were expressed as proportions, and the $\chi^{2}$ test or Fisher's exact test was used to analyse group differences across categorical variables.

Separate survival analysis was performed and Kaplan-Meier (K-M) curves were plotted to depict cumulative rates of local recurrence at various time points. Time for recurrence was defined as interval between treatment and time of local tumour recurrence. Comparison between the rates of local recurrence between different subgroups was analysed using the logrank test.

The survival probability for local recurrence was assessed using the Cox proportional hazards models and displayed using HRs. Covariates used for adjusting HRs were those with a $\mathrm{p}$ value $<0.1$ in univariate models and those that have been shown to influence local recurrence in previous studies.

Data were entered in the online data registry and maintained in Microsoft Access. Data were analysed using STATA (version 12.1, I/C, Fort Worth, Texas, USA) statistical analysis software package, and $\mathrm{p}<0.05$ was considered statistically significant.

\section{RESULTS}

The registry collected information on 288 eyes of 288 patients with conjunctival melanoma. The mean $( \pm S D)$ age at presentation was $59.7 \pm 16.8$ years (median $=49.4$ years, $\mathrm{IQR}=36-71$ years, range $=15-95$ years). With regards to patients, $51 \%$ were men $(n=147 / 288)$ and 53\% had right eye involvement $(n=154 /$ 288). Race and ethnicity data were not collected.

\section{Clinical features}

The primary tumour characteristics were identified in $92.7 \%$ eyes $(n=267 / 288)$.

\section{Tumour location}

The tumour was identified as bulbar in $83.5 \%$ eyes $(n=223 / 267)$ and non-bulbar in $16.5 \%$ eyes $(n=44 / 267)$.

\section{Tumour extent}

Conjunctival zones of tumour margin were listed in postero-anterior order, with cornea being the posterior limit and eyelid skin being the anterior limit (figure 1). The posterior margin of tumour was limited to the bulbar conjunctiva in $24.3 \%(n=65 / 267)$ followed by cornea in $20.2 \%(n=54 / 267)$, limbus $15.4 \%(n=41 / 267)$, fornix in $2.6 \%$ $(\mathrm{n}=7 / 267)$, caruncle in $2 \%(\mathrm{n}=5 / 267)$, plica in $2 \%(\mathrm{n}=5 / 267)$, tarsal conjunctiva in $1.5 \%(n=4 / 267)$, lid margin in $0.7 \%(n=2 / 267)$ and palpebral conjunctiva in $0.3 \%(n=1 / 267)$. The anterior margin of the tumour was limited to bulbar conjunctiva in $45.7 \%$ eyes $(n=122 / 267)$ followed by the limbus in $5.6 \%$ eyes $(n=15 / 267)$, cornea in $4.9 \%(n=13 / 267)$, fornix in $3 \%(n=8 / 267)$, tarsal conjunctiva in $2.6 \%(n=7 / 267)$, lid margin in $1.5 \%(n=4 / 267)$, caruncle in $1 \%(n=3 / 267)$ and eyelid skin in $1 \%(n=3 / 267)$. Overall, caruncular involvement was seen in $11.1 \%$ eyes $(n=32 / 288)$, plica in $10.8 \%$ eyes $(n=31 / 287)$ and eyelid in $3.5 \%$ eyes $(n=10 / 288)$.

\section{Tumour nodularity}

Nodular component to the tumour was seen in $72.3 \%$ eyes $(n=193 / 267)$ and extended for a mean of 2 clock hours (median $=2$ clock hours, range $=1-10$ clock hours, $S D=2.4$ ).

\section{Tumour pigmentation}

The tumour colour was documented in 123 eyes. Dark brown $(\mathrm{n}=47 / 123,38.2 \%)$ was most common followed by light brown $(n=27 / 123,21.9 \%)$, pink $(n=23 / 123,18.7 \%)$, black $(n=11 / 123$, 
Table 1 Conjunctival melanoma: the eighth edition of the American Joint Committee on Cancer (AJCC) staging manual

\begin{tabular}{|c|c|c|c|}
\hline \multicolumn{4}{|c|}{ Definition of primary tumour $(\mathrm{T})$} \\
\hline \multicolumn{2}{|c|}{ Clinical tumour (cT) } & \multicolumn{2}{|c|}{ Pathological tumour (pT) } \\
\hline cT category & cT criteria & pT category & pT criteria \\
\hline \multirow[t]{2}{*}{ TO } & No evidence of primary tumour & T0 & No evidence of primary tumour \\
\hline & & Tis & Melanoma confined to conjunctival epithelium \\
\hline $\mathrm{T} 1$ & Tumour of the bulbar conjunctiva & & \\
\hline $\mathrm{T} 1 \mathrm{~b}$ & $\geq 1$ to $<2$ quadrants & & \\
\hline T1c & $\geq 2$ to $<3$ quadrants & $\mathrm{T} 1 \mathrm{~b}$ & $\begin{array}{l}\text { Tumour of the bulbar conjunctiva with invasion of the substantia propria, more than } \\
2.0 \mathrm{~mm} \text { in thickness }\end{array}$ \\
\hline T1d & $\geq 3$ quadrants & & \\
\hline $\mathrm{T} 2$ & Tumour of the non-bulbar (forniceal, palpebral, tarsa & al) conjunctiva a & tumour involving the caruncle \\
\hline $\mathrm{T} 2 \mathrm{c}$ & $\begin{array}{l}\text { Caruncular, and } \leq 1 \text { quadrant of the non-bulbar } \\
\text { conjunctiva involved }\end{array}$ & $\mathrm{T} 2 \mathrm{~b}$ & $\begin{array}{l}\text { Tumour of the non-bulbar conjunctiva with invasion of the substantia propria, more } \\
\text { than } 2.0 \mathrm{~mm} \text { in thickness }\end{array}$ \\
\hline $\mathrm{T} 2 \mathrm{~d}$ & $\begin{array}{l}\text { Caruncular, and }>1 \text { quadrant of the non-bulbar } \\
\text { conjunctiva involved }\end{array}$ & & \\
\hline $\mathrm{T} 3$ & Tumour of any size with local invasion & & \\
\hline T3a & Globe & T3a & Globe \\
\hline $\mathrm{T} 3 \mathrm{~b}$ & Eyelid & $\mathrm{T} 3 \mathrm{~b}$ & Eyelid \\
\hline $\mathrm{T} 3 \mathrm{c}$ & Orbit & $\mathrm{T} 3 \mathrm{C}$ & Orbit \\
\hline T3d & $\begin{array}{l}\text { Nasolacrimal duct and/or lacrimal sac and/or } \\
\text { paranasal sinuses }\end{array}$ & T3d & Nasolacrimal duct and/or lacrimal sac and/or paranasal sinuses \\
\hline T4 & $\begin{array}{l}\text { Tumour of any size with invasion of the central } \\
\text { nervous system }\end{array}$ & $\mathrm{T} 4$ & Tumour of any size with invasion of the central nervous system \\
\hline
\end{tabular}

em dash, not calculable.

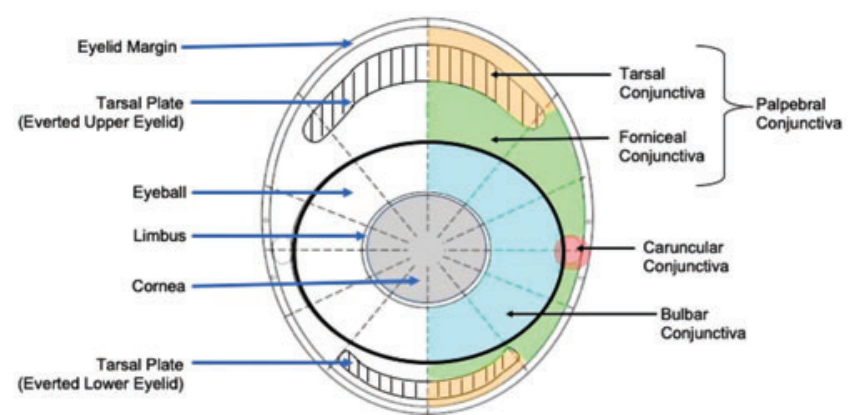

Figure 1 Diagram showing the relevant anatomy and radial clock hours used for AJCC staging.ref 6 (Illustration Adapted by Puneet Jain).

$8.9 \%)$, red $(n=8 / 123,6.5 \%)$, grey $(n=3 / 123,2.4 \%)$ and two each were defined as yellow or white in colour.

Tumour ulceration

Tumour surface ulceration was noted in 9.7\% eyes $(n=14 / 143)$.

\section{Acquired melanosis}

Acquired melanosis was noted in $31.9 \%$ eyes $(n=92 / 288)$; these tumours were most commonly light brown in colour $(n=41 / 92,44.6 \%)$ followed by dark brown $(n=13 / 92$, $14.1 \%)$ and rarely pink $(n=3 / 92,3.2 \%)$. The melanosis extended for 2 clock hours (mean $=2.03 \pm 3.8$ clock hours, median $=4$ clock hours, range $=1-10$ clock hours) and $78.2 \%(\mathrm{n}=72 / 92)$ had a nodular component.

Tumour invasion

Eyelid invasion was seen in $3.5 \%$ eyes $(n=10 / 288)$ and orbital invasion in $1.4 \%$ eyes $(n=4 / 288)$. Invasion into the globe or paranasal sinuses was not noted.

\section{Pathological features}

Specimens for histopathological examination were available in 271 eyes $(n=271 / 288,94 \%)$. The mean diameter of the melanoma was $7.3 \pm 4.4 \mathrm{~mm}$ (median $=6.25 \mathrm{~mm}, \mathrm{IQR}=4-10 \mathrm{~mm}$, range $=0.9-27 \mathrm{~mm}$ ) while the mean thickness was $1.9 \pm 2.2 \mathrm{~mm}$ (median=1 $\mathrm{mm}, \mathrm{IQR}=0.6-2.5 \mathrm{~mm}$, range $=0.2-16 \mathrm{~mm}$ ). Maximum tumour thickness was $>2 \mathrm{~mm}$ in $27 \%(\mathrm{n}=54 / 201)$ and $\leq 2 \mathrm{~mm}$ in $73 \%(\mathrm{n}=147 / 201)$. Lymphatic invasion was noted in $6.8 \%(n=10 / 148)$.

\section{Nodal and systemic spread}

Lymph node involvement at presentation was noted in 13 cases $(n=13 / 288,4.5 \%)$, involving ipsilateral cervical $(n=7 / 13$, $53.8 \%)$, pre-auricular $(\mathrm{n}=7 / 13,53.8 \%)$, post-auricular $(\mathrm{n}=2 /$ $13,15.3 \%)$, submandibular nodes $(\mathrm{n}=2 / 13,15.3 \%)$ and uncategorised in four cases.

At presentation, systemic metastasis was seen in five patients $(\mathrm{n}=5 / 288,1.7 \%)$ with three patients having lung and two having 
liver metastasis. Over a median follow-up of 4.3 years (IQR $=2.9-6$ years), 24 patients $(n=24 / 283,8.5 \%)$ developed metastasis. In this group, liver was the most common site $(\mathrm{n}=11 / 24,45.8 \%)$, followed by lungs $(\mathrm{n}=9 / 24,37.5 \%)$, brain $(n=3 / 24,12.5 \%)$, bone $(n=2 / 24,8.3 \%)$, abdomen $(n=2 / 24$, $8.3 \%)$ and one each $(n=1 / 24,4.2 \%)$ of parotid gland, skin, peritoneum and bladder. Metastatic sites were undocumented in three patients $(n=3 / 24,12.5 \%)$. Multi-organ metastases were seen in 10 patients $(n=10 / 24,41.7 \%)$.

\section{TNM classification}

The eighth edition of the AJCC tumor node metastasis (TNM) conjunctival melanoma classification was employed. The clinical T-categories (cT) were cT1 $(n=218,75.7 \%)$, followed by cT2 $(\mathrm{n}=34,11.8 \%)$, cT3 $(\mathrm{n}=15,5.2 \%)$ and $\mathrm{cTx}(\mathrm{n}=21,7.3 \%)$, as shown in table 2 . The pathological T-categories (pT) were pTis $(\mathrm{n}=43,14.9 \%), \mathrm{pT} 1(\mathrm{n}=169,58.7 \%), \mathrm{pT} 2(\mathrm{n}=33,11.5 \%), \mathrm{pT} 3$ $(\mathrm{n}=12,4.2 \%)$ and $\mathrm{pTx}(\mathrm{n}=31,10.8 \%)$, as shown in table 3 . There were no T4 tumours in this study.

Nodal status at presentation was N0 $(n=209,72.6 \%)$ followed by $\mathrm{N} 1 \quad(\mathrm{n}=13,4.5 \%)$ and $\mathrm{Nx}(\mathrm{n}=66,22.9 \%)$. Metastasis classification at presentation was M0 $(n=216$, $75 \%)$, M1 ( $\mathrm{n}=5,1.7 \%)$.

\section{Treatment}

Primary treatment in order of frequency used included wide local excision $(n=161 / 288,55.9 \%)$ followed by excision biopsy with cryotherapy $(\mathrm{n}=108 / 288,37.5 \%)$, exenteration $(\mathrm{n}=5 /$ $288,1.7 \%)$, topical MMC ( $\mathrm{n}=2 / 288,1 \%)$, topical IFN $2 \mathrm{~b}$ $(n=2 / 288,1 \%)$ and one patient each underwent plaque brachytherapy and enucleation. Primary treatment was not specified in eight patients.

Adjuvant treatment included topical MMC $(n=107 / 288$, $37.1 \%)$, plaque brachytherapy $(\mathrm{n}=55 / 288,19.1 \%)$ including strontium $(\mathrm{n}=31 / 288,10.7 \%)$ or ruthenium brachytherapy $(n=8 / 288,2.7 \%)$, proton beam therapy $(n=36 / 288,13.5 \%)$, topical IFN $\alpha 2 b(n=20 / 288,6.9 \%)$, EBRT $(n=15 / 288,5.2 \%)$ and two patients received topical 5-FU). Overall, 199 eyes ( $n=199 / 288,69.1 \%)$ received adjuvant therapy. Eleven patients eventually underwent secondary exenteration $(n=11 /$ 282, 3.9\%).

The median follow-up time was 4.4 years $(\mathrm{IQR}=2.3-6.9$ years; range $=1$ month -14.3 years).

\section{Local recurrence}

Fifty-five eyes $(n=55 / 288,19.1 \%)$ showed local recurrence at a median of 3.6 years $(\mathrm{IQR}=1.8-5.7$ years,

Table 2 Cumulative local recurrence rates based on clinical AJCC stage

\begin{tabular}{|c|c|c|c|c|c|}
\hline \multirow[b]{2}{*}{ Clinical T-category (cT) } & \multirow[b]{2}{*}{ No. patients } & \multirow[b]{2}{*}{ No. recurred (\%) } & \multicolumn{3}{|c|}{ Cumulative $\%$ of local recurrence $(95 \% \mathrm{Cl})$} \\
\hline & & & 1 year & 5 years & 10 years \\
\hline Tx & 12 & $2(17)$ & $10.8 \%(3 \%$ to $37 \%)$ & $10.8 \%(3-37 \%)$ & - \\
\hline T1a & 115 & $21(17)$ & $3.7 \%(1 \%$ to $9 \%)$ & $15.9 \%(10 \%$ to $25 \%)$ & $36.6 \%(21 \%$ to $58 \%)$ \\
\hline $\mathrm{T} 1 \mathrm{~b}$ & 62 & $9(14)$ & $3.4 \%(0.8 \%$ to $13 \%)$ & $12.7 \%(6 \%$ to $27 \%)$ & $29.1 \%(12 \%$ to $60 \%)$ \\
\hline T1c & 8 & 0 & 0 & 0 & - \\
\hline $\mathrm{T}^{*}$ & 5 & $2(40)$ & 0 & $40 \%(12 \%$ to $87 \%)$ & $40 \%(12 \%$ to $87 \%)$ \\
\hline $\mathrm{T} 2 \mathrm{a}$ & 8 & $1(12.5)$ & 0 & $14.3 \%(2 \%$ to $66 \%)$ & - \\
\hline $\mathrm{T} 2 \mathrm{~b}$ & 5 & $1(20)$ & 0 & $20 \%$ (3\% to $79 \%)$ & - \\
\hline $\mathrm{T} 2 \mathrm{c}$ & 8 & $2(25)$ & $16(2 \%$ to $73 \%)$ & - & - \\
\hline $\mathrm{T} 2 \mathrm{~d}$ & 7 & 1 (14) & 0 & 0 & 0 \\
\hline
\end{tabular}

*Subgroup data not available.

AJCC, American Joint Committee on Cancer; em dash, not calculable.

Table 3 Cumulative local recurrence rates based on pathological AJCC stage

\begin{tabular}{|c|c|c|c|c|c|}
\hline \multirow[b]{2}{*}{ Pathology T-category (pT) } & \multirow[b]{2}{*}{ No. patients } & \multirow[b]{2}{*}{ No. recurred (\%) } & \multicolumn{3}{|c|}{ Cumulative $\%$ of local recurrence $(95 \% \mathrm{Cl})$} \\
\hline & & & 1 year & 5 years & 10 years \\
\hline $\mathrm{Tx}$ & 31 & $5(16)$ & $15.3 \%(6 \%$ to $35.7 \%)$ & $15.3 \%(6 \%$ to $35.7 \%)$ & - \\
\hline Tis & 43 & $8(17)$ & 0 & $12.4(4.8 \%$ to $29.7 \%)$ & $37.4 \%(15.3 \%$ to $73.4 \%)$ \\
\hline $\mathrm{T} 1 \mathrm{a}$ & 123 & $27(22)$ & $5.2 \%(2.4 \%$ to $11.3 \%)$ & $19.1 \%(12.5 \%$ to $28.6 \%)$ & $40.3 \%(26.6 \%$ to $57.7 \%)$ \\
\hline $\mathrm{T} 1 \mathrm{~b}$ & 46 & $6(13)$ & $7.2 \%(2.4 \%$ to $20.6 \%)$ & $17.4 \%(7.9 \%$ to $35.8 \%)$ & $17.4 \%(7.9 \%$ to $35.8 \%)$ \\
\hline $\mathrm{T} 2 \mathrm{a}$ & 12 & $2(17)$ & 0 & $21.4 \%(55.5 \%$ to $63.9 \%)$ & $21.4 \%(55.5 \%$ to $63.9 \%)$ \\
\hline $\mathrm{T} 2 \mathrm{~b}$ & 21 & $5(24)$ & $5.3 \%(0.7 \%$ to $31.2 \%)$ & $33.4 \%(14.3 \%$ to $65.6 \%)$ & $33.4 \%(14.3 \%$ to $65.6 \%)$ \\
\hline T3a & 1 & 0 & - & - & - \\
\hline $\mathrm{T} 3 \mathrm{~b}$ & 6 & $1(17)$ & 0 & - & - \\
\hline $\mathrm{T} 3 \mathrm{c}$ & 5 & $1(20)$ & 0 & - & - \\
\hline
\end{tabular}

AJCC, American Joint Committee on Cancer; em dash, not calculable. 
range $=1.1-13.8$ years) after treatment. Of these 55 eyes, 32 $(n=32 / 161=19.8 \%)$ had wide local excision while $23(n=23 /$ $108=21.3 \%)$ had excision biopsy with cryotherapy $(\mathrm{p}=0.70)$. Local recurrence was seen in 18 eyes $(n=18 / 77,23.4 \%)$ without any adjuvant therapy and in 37 eyes $(n=37 / 199,8.5 \%)$ when adjuvant therapy was employed $(\mathrm{p}=0.32)$. The cumulative rate of local recurrence was progressive at 5.4\% (3.2-8.9\%), 19.3\% $(14.4-25.5 \%)$ and $36.9 \%(26.5-49.9 \%)$ at 1,5 and 10 years of follow-up, respectively.

\section{Cumulative local recurrence rates according to clinical stage}

The cumulative local recurrence was 5.1\% (2.7-9.2\%), 17.6\% $(12.5-24.4 \%)$ and $37.2 \%(25.5-52 \%)$ at 1,5 and 10 years, respectively, for T1 disease while it was 3.3\% (0.5-21.4\%) at 1 year and $26.8 \%(12.2-52.6 \%)$ at both 5 and 10 years for T2 disease. Cumulative local recurrence rate was higher for T3 disease that is, 9.1\% (1.3-49.2\%) at 1 year and $45.5 \%(19.3-82.1 \%)$ at 5 years. The local recurrence rate of subgroups by clinical stage is shown in table 2 . There was no statistically significant difference in the cumulative rate of local recurrence between different clinical stages of disease $(\mathrm{p}=0.28$, logrank test). The K-M curves showing comparative local recurrence curves for cT1, cT2 and cT3 disease are shown in figure 2 .

\section{Cumulative local recurrence rates according to pathological stage}

The cumulative rate of local recurrence was 5.8\% (3.1-10.8\%), $18.7 \%(12.9-26.8 \%)$ and $37.1 \%(24.8-52.8 \%)$ at 1,5 and 10 years of follow-up for pT1 disease, espectively. There were $3.2 \%(0.5-20.8 \%)$ at 1 year and $29.9 \%(14.4-55.4 \%)$ at 5 and 10 years for pT2 tumours. There were only 12 cases of pT3 disease and 2 recurrences $(n=2)$, which prevented significance in calculation of recurrence. The pTis tumours showed $0 \%$, $12.4 \%(4.8-29.7 \%)$ and $37.4(15.3-73.4 \%)$ recurrence at 1,5 and 10 years. The local recurrence rate of subgroups of pathological stages is shown in table 3 . However, there were no statistically significant difference in cumulative rate of local recurrence between eyes with different pathological stages of disease (logrank, $\mathrm{p}=0.92$ ). The K-M curves showing comparative local recurrence rates for pT1, pT2 and pT3 is shown in figure 3 .

On multivariable Cox proportional hazards analysis (table 4), eyes with T2 and T3 disease were seen to have more than twice the risk of local recurrence compared to eyes with T1 disease.

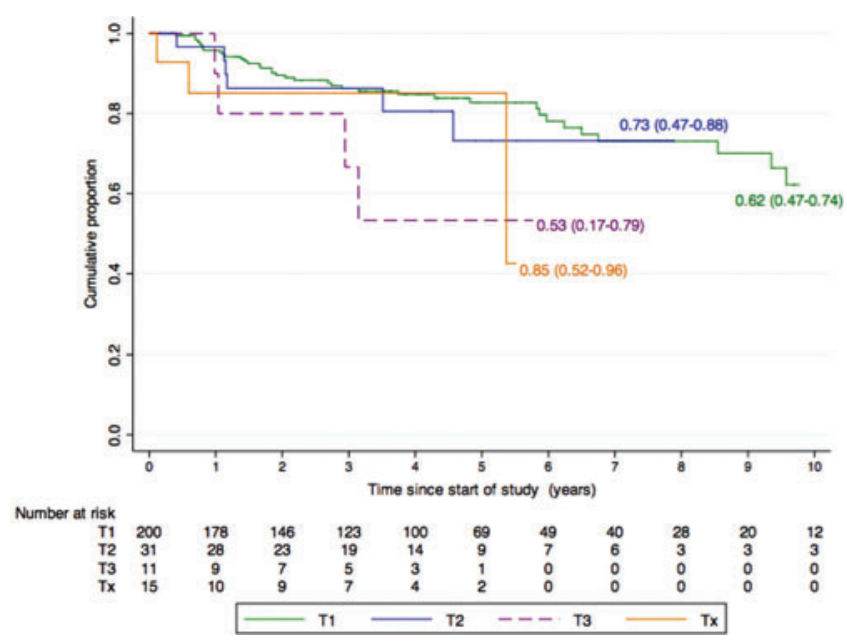

Figure 2 Kaplan-Meier survival curves showing cumulative local recurrence rates for patients with different clinical T-staging.

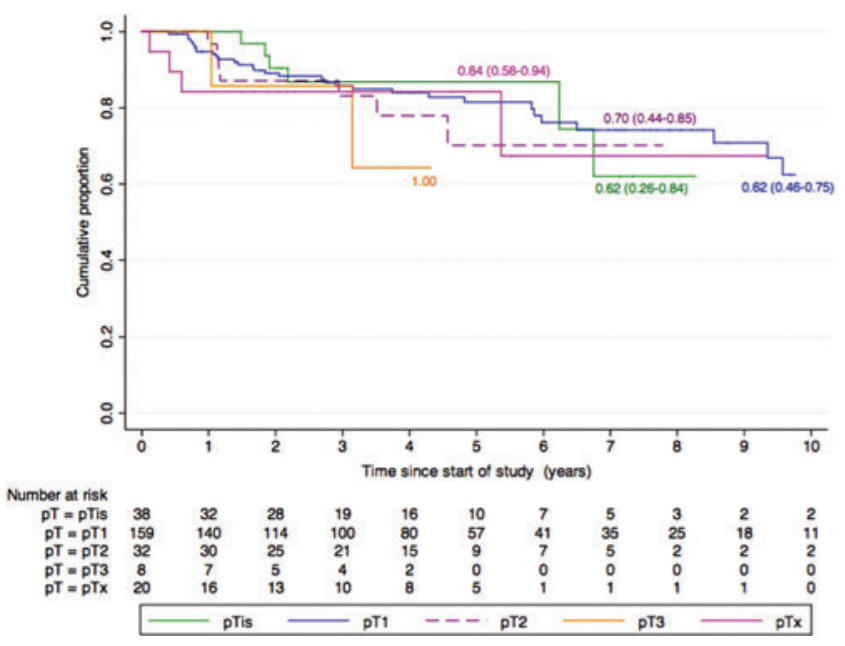

Figure 3 Kaplan-Meier survival curves showing cumulative local recurrence rates for patients with different pathological T-staging.

However, the increased risk of recurrence was statistically significant only for $\mathrm{T} 3$ disease $(\mathrm{HR}=8.06,95 \%$ CI 1.55 to 41.67 , $\mathrm{p}=0.013)$. No other factors such as tumour ulceration, plica and caruncle involvement, presence of invasive melanoma and tumour thickness reached statistical significance for increased risk of local recurrence (table 4).

\section{Survival}

We have recently published the cumulative mortality rates from the same data set. ${ }^{5}$ That research demonstrated the predictive value of AJCC staging for metastasis-related mortality.

\section{DISCUSSION}

Herein, we present the results of the first, large, multicentre, international, internet-based registry study on conjunctival melanoma. The local recurrence rate was $19.1 \%$ at a median followup of 3.6 years (43 months). Overall cumulative rates of local recurrence were found to be progressive at 5.4\% at 1 year, $19.3 \%$ at 5 years and $36.9 \%$ at 10 years of follow-up. The eighth edition of the AJCC clinical staging was predictive of local recurrence in that eyes with T3 disease had more than twice the risk of local recurrence compared to eyes with T1 disease $(\mathrm{p}=0.013)$. Herein, we found tumour thickness, plica and/or caruncle involvement and tumour ulceration were not associated with increased risk of local recurrence. Upon spread, nodal involvement was less commonly reported than systemic metastasis.

In review of the literature on conjunctival melanoma, the mean age at diagnosis for conjunctival melanoma varies between 54 and 67 years, and tends to be lower in Asian and African populations. ${ }^{12} 1316{ }^{30-36}$ In our study group, the mean age was 60 years and with no pediatric patients. ${ }^{37} 38$ Like most studies, ours revealed no sex predilection. ${ }^{12} 303335$ That said, both male and female preponderance has been reported. ${ }^{11} 13163139$

Conjunctival melanoma has been reported to arise from acquired melanosis in 26-93\% cases. ${ }^{1} 412131630313435$ In our study, acquired melanosis was noted in $32 \%$. Most of the tumours reported in this registry were pigmented (69\%) and nodular (72\%) consistent with prior reports. ${ }^{12} 13343538$

The orbital exenteration rates in the past 4 decades have ranged between 8\% and 50\%. ${ }^{12} 1315163034-36$ The exenteration rate in our study was relatively low at $5.5 \%$. Although no patients in the study underwent an incisional biopsy, it is worth 
Table 4 Cox proportional hazards model for predicting local recurrence

\begin{tabular}{|c|c|c|c|c|c|c|}
\hline \multirow[b]{2}{*}{ Variable } & \multirow[b]{2}{*}{ No. patients (\%) } & \multirow[b]{2}{*}{ Interval } & \multicolumn{2}{|c|}{ Univariate analysis } & \multicolumn{2}{|c|}{ Multivariable analysis } \\
\hline & & & HR & $95 \% \mathrm{Cl}$ & HR & $95 \% \mathrm{Cl}$ \\
\hline Age & $288(100)$ & 1-year increment & 1.02 & 1.00 to 1.04 & 1.02 & 0.99 to 1.06 \\
\hline Male & $147(51)$ & Versus female & 0.97 & 0.53 to 1.63 & - & - \\
\hline Ulceration $(n=143)$ & $14(10)$ & Versus no ulceration & 1.46 & 0.30 to 6.21 & 0.53 & 0.06 to 4.46 \\
\hline Plica involved $(n=287)$ & $31(11)$ & Versus no involvement & 0.84 & 0.59 to 1.20 & 0.33 & 0.03 to 3.13 \\
\hline Caruncle involved $(n=288)$ & $32(11)$ & Versus no involvement & 0.81 & 0.57 to 1.16 & 1.18 & 0.15 to 9.25 \\
\hline Tumour stage (cT2) & 34 & Versus T1 & 0.99 & 0.41 to 2.38 & 2.92 & 0.66 to 12.84 \\
\hline Tumour Stage (cT3) & 15 & Versus T1 & $3.06^{*}$ & 1.07 to 8.70 & 8.06 ** & 1.55 to 41.67 \\
\hline Tumour stage $(\mathrm{Tx})$ & 21 & Versus T1 & 1.89 & 0.57 to 6.19 & 2.15 & 0.70 to 7.21 \\
\hline Invasive melanoma $(n=288)$ & $219(76)$ & Versus no invasion & 1.01 & 0.68 to 1.49 & 0.82 & 0.59 to 1.14 \\
\hline Tumour thickness $(n=201)$ & $201(70)$ & $1 \mathrm{~mm}$ increment & 0.99 & 0.83 to 1.17 & 0.82 & 0.59 to 1.14 \\
\hline
\end{tabular}

${ }^{*} p=0.04$.

${ }^{* *} \mathrm{p}=0.013$.

$\mathrm{tn}=$ number of reports available.

$\mathrm{Cl}$, confidence interval; $\mathrm{HR}$, hazard ratio. em dash, not calculable.

mentioning that incisional biopsies have been associated with increased risk of metastasis. ${ }^{12}{ }^{34}$ Clearly, subtotal excisions lead to a haemorrhagic, scarred tumour bed that is more difficult to define subsequent surgical margins. As seen with conjunctival squamous carcinoma, it is reasonable to assume that treatment of a surgically altered conjunctival melanoma tumour bed is less likely to be curative. ${ }^{40}$

Local recurrence in our study was reported to occur in 19\% of patients as compared to reports ranging from 11\% to 69\% in published studies. $^{12} 1315163034354142$ A few studies have documented the median time to local recurrence as 11-17 months. ${ }^{13} 4243$ Comparatively, in our study, median local recurrence time was 13 months.

The cumulative 5-year and 10-year local recurrence data range from $26 \%$ to $51 \%$ and $51 \%$ to $60 \%$, respectively, from singlecentre studies. ${ }^{1342} 43$ Our multicentre data revealed cumulative 5 -year local recurrence rate to be $19 \%$ and 10 -year rate at $37 \%$. Our cumulative recurrence rates were comparable for various cT and pT-categories, implying that clinical AJCC staging is as useful as pathological staging for gauging local recurrence risk.

Multivariate Cox proportional hazards analysis revealed that higher clinical T-staging was the only factor predictive of local recurrence in our study. ${ }^{1641}$ Unlike prior reports, we found that tumour thickness, ulceration, plica and caruncle involvement did not significantly influence local recurrence rates (table 4). ${ }^{1} 15 \quad 1632343841$

In our study, there was no difference in local recurrence rates in patients who underwent wide excision alone (19.8\%) compared to excision with cryotherapy $(21.3 \%, \mathrm{p}=0.70)$. Esmaeli et al reported similar outcomes abeit in a smaller sample. ${ }^{42}$ In contrast to reported literature, administration of adjuvant therapy (cryotherapy, plaque brachytherapy or topical chemotherapy) did not significantly alter local recurrence rates $(\mathrm{p}=0.32) .^{121641}$ This finding supports etiological theories that include therapeutic miss of nonpigmented tumour, surgical tumour transplantation and that second primary tumours are arising from conjunctiva at risk. This finding also supports the concept that conjunctival melanoma is a multicentric disease and recurrences may be second tumours arising from other foci of clinically undetected in situ, sine pigmento or microinvasive melanoma. In addition, the possibility of adjunctive therapy being biased towards unfavourable tumours cannot be determined. ${ }^{44} 45$
In this study, data collection was subjective to each centre's specific methods of diagnosis and treatment. There is predominance of early AJCC-staged tumours which likely reflects the patient distribution typically presenting to these centres. This study includes a large number of conjunctival melanoma patients from multiple, international subspeciality eye cancer centres. Thus, this research provides a unique perspective of worldwide care, its risks and the potential benefits of current treatment.

In conclusion, this study suggests that AJCC T-staging can be used to predict local tumour control after treatment. It showed that within a decade of treatment of conjunctival melanomas, the incidence of recurrence progressively increased despite subspeciality management. Multicentre data-sharing was used to reveal critical information on local recurrence of conjunctival melanoma.

\section{Twitter https://twitter.com/paulfingermd.}

Acknowledgements Yuliya Gavrylyuk IMG MHA, Princess Margaret Cancer Centre, Toronto, Ontario, Canada, assisted with multicentre institutional review board, ethics committee, privacy and other contractual relationships. Dr Sabyasachi Sengupta, Sengupta Research Academy, Maharashtra, India, assisted with statistics and manuscript revisions. They were compensated for their work.

Collaborators American Joint Committee on Cancer Ophthalmic Oncology Task Force, Paul T Finger, Sarah E Coupland, Daniel M Albert, Anush G Amiryan, Svetlana Saakyan Claudia Auw-Hädrich, Diane Baker, Raymond Barnhill, José M Caminal, William L Caroll, Nathalie Cassoux, Laurence G Desjardins, François Doz, Gaelle Pierron, Jaume Catalá-Mora, Guillermo Chantada, Patricia Chévez-Barrios, R Max Conway, Bertil E Damato, Hakan Demirci, Jonathan J Dutton, Bita Esmaeli, Victor G Prieto, Michelle Williams, Brenda L Gallie, Gerardo F Graue, Hans E Grossniklaus, Steffen Heegaard, Leonard M Holbach, Santosh G Honavar, Martine J Jager, Tero Kivelä, Emma Kujala, Livia Lumbroso-Le Rouic, Ashwin C Mallipatna, Giulio M Modorati, Francis L Munier, Timothy G Murray, Anna C Pavlick, Jacob Pe'er, David E Pelayes, Manuel Jorge Rodriguez, Wolfgang A G Sauerwein, Ekaterina Semenova, Stefan Seregard, Carol Shields, E Rand Simpson, Arun D Singh, Shigenobu Suzuki, Mary Kay Washington, Valerie A White, Mathew W Wilson, Christian W Wittekind, Vivian Yin.

Contributors All of the authors participated in obtaining Internal Review Board and ethics approvals from their local institutions. They entered anonymised data from their local patients. They were sent the original manuscript for critical review, revision and approval.

Funding The Myrna and John Daniels Charitable Trust, the Paul Finger Fund at Princess Margaret Cancer Center and The Eye Cancer Foundation provided monetary support to the Princess Margaret Cancer Centre's Health Informatics Research Program, which has participated in the design, construction and maintenance of this data registry for conjunctival melanoma. Dr Puneet Jain received an ophthalmic oncology fellowship grant from The Eye Cancer Foundation (http://eyecancercure.com).

Competing interests None declared. 
Patient consent for publication Not required.

Provenance and peer review statement Not commissioned; externally peer reviewed.

Data availability statement All data relevant to the study are included in the article or uploaded as supplemental information.

Open access This is an open access article distributed in accordance with the Creative Commons Attribution Non Commercial (CC BY-NC 4.0) license, which permits others to distribute, remix, adapt, build upon this work non-commercially, and license their derivative works on different terms, provided the original work is properly cited, appropriate credit is given, any changes made indicated, and the use is noncommercial. See: http://creativecommons.org/licenses/by-nc/4.0/.

\section{ORCID iD}

Paul T Finger http://orcid.org/0000-0002-8111-3896

\section{REFERENCES}

1 Wong JR, Nanji AA, Galor A, et al. Management of conjunctival malignant melanoma: a review and update. Expert Rev Ophthalmol 2014;9:185-204.

2 Li Y, Fan X, Conjunctival Melanoma JR. Update on management. Int Ophthalmol Clin 2019:59:27-35.

3 Yu G-P, Hu D-N, McCormick S, et al. Conjunctival melanoma: is it increasing in the United States? Am J Ophthalmol 2003:135:800-6.

4 Vora GK, Demirci H, Marr B, et al. Advances in the management of conjunctival melanoma. Surv Ophthalmol 2017:62:26-42.

5 Jain P, Finger PT, Damato B, et al. Multicenter, international assessment of the eighth edition of the American Joint Committee on Cancer cancer staging manual for conjunctival melanoma. JAMA Ophthalmol 2019;137:905-11.

6 Coupland S, Barnhill R, Conway R, et al. Conjunctival Melanoma. In: Amin MB, Edge S, Greene F, eds. AJCC Cancer Staging Manual. 8th edn. Springer International Publishing: American Joint Commission on Cancer, 2017: 803-11.

7 Finger PT, Milner MS, McCormick SA. Topical chemotherapy for conjunctival melanoma. Br J Ophthalmol 1993;77:751-3.

8 Finger PT, Czechonska G, Liarikos S. Topical mitomycin C chemotherapy for conjunctival melanoma and PAM with atypia. Br J Ophthalmol 1998;82:476-9.

9 Kurli M, Finger PT. Topical mitomycin chemotherapy for conjunctival malignant melanoma and primary acquired melanosis with atypia: 12 years' experience. Graefe's Arch Clin Exp Ophthalmol 2005:243:1108-14.

10 Finger PT, Sedeek RW, Chin KJ. Topical interferon alfa in the treatment of conjunctival melanoma and primary acquired melanosis complex. Am J Ophthalmol 2008:145:124-9.

11 Paridaens ADA, Minassian DC, ACE M, et al. Prognostic factors in primary malignant melanoma of the conjunctiva: a clinicopathological study of 256 cases. Br J Ophthalmol 1994;78:252-9.

12 Larsen AC, Dahmcke CM, Dahl C et al. A retrospective review of conjunctival melanoma presentation, treatment, and outcome and an investigation of features associated with BRAF mutations. JAMA Ophthalmol 2015:133:1295-303.

13 Zhou C, Wang Y, Jia R, et al. Conjunctival melanoma in Chinese patients: local recurrence, metastasis, mortality, and comparisons with Caucasian patients. Investig Ophthalmol Vis Sci 2017:58:5452-9.

14 Tuomaala S, Eskelin S, Tarkkanen A, et al. Population-based assessment of clinical characteristics predicting outcome of conjunctival melanoma in whites. Invest Ophthalmol Vis Sci 2002;43:3399-408.

15 Missotten GS, Keijser S, RJW DK, et al. Conjunctival melanoma in the Netherlands: a nationwide study. Investig Ophthalmol Vis Sci 2005;46:75-82

16 Werschnik C, Lommatzsch PK. Long-term follow-up of patients with conjunctival melanoma. Am J Clin Oncol Cancer Clin Trials 2002;25:248-55.

17 Rasmussen PK, Coupland SE, Finger PT, et al. Ocular adnexal follicular lymphoma: a multicenter international study. JAMA Ophthalmol 2014;132:851-8.

18 Munch-Petersen HD, Rasmussen PK, Coupland SE, et al. Ocular adnexal diffuse large b-cell lymphoma: a multicenter international study. JAMA Ophthalmol 2015;133:165-73
19 Knudsen MKH, Rasmussen PK, Coupland SE, et al. Clinicopathological features of ocular adnexal mantle-cell lymphoma in an international multicenter cohort. JAMA Ophthalmol 2017;135:1367-74.

20 Olsen TG, Holm F, Mikkelsen LH, et al. Orbital Lymphoma: an international multicenter retrospective study. Am J Ophthalmol 2019;199:44-57.

21 Khan S, Finger PT, Yu GP, et al. Clinical and pathologic characteristics of biopsy-proven iris melanoma: a multicenter international study. Arch Ophthalmol 2012;130:57-64.

22 Gallie BL, Simpson ER, Saakyan S, et al. Local recurrence significantly increases the risk of metastatic uveal melanoma. Ophthalmology 2016;123:86-91.

23 Simpson ER, Gallie B, Laperrierre N, et al. The American Brachytherapy Society consensus guidelines for plaque brachytherapy of uveal melanoma and retinoblastoma. Brachytherapy 2014;13:1-14.

24 Zhou C, Wu F, Chai P, et al. Mohs micrographic surgery for eyelid sebaceous carcinoma: a multicenter cohort of 360 patients. J Am Acad Dermatol 2019;80:1608-17.

25 Svendsen FH, Rasmussen PK, Coupland SE, et al. Lymphoma of the eyelid: an international multicenter retrospective study. Am J Ophthalmol 2017;177:58-68.

26 Simpson E, Gallie BL, Saakyan S, et al. 7th edition classification of uveal melanoma. JAMA Ophthalmol 2015;133:376-83.

27 Finger PT. Foundational elements for collaboration in ophthalmic oncology. Ophthalmol Retina 2017;1:263-5.

28 Kurli M, Chin K, Finger PT. Whole-body 18 FDG PET/CT imaging for lymph node and metastatic staging of conjunctival melanoma. Br J Ophthalmol 2008;92:479-82.

29 Damian A, Gaudiano J, Engler H, et al. ${ }^{18} \mathrm{~F}-\mathrm{FDG}$ PET-CT for staging of conjunctival melanoma. World J Nucl Med 2013;12:45-7.

30 Brouwer NJ, Marinkovic M, Van Duinen SG, et al. Treatment of conjunctival melanoma in a dutch referral centre. Br J Ophthalmol 2018;102:1277-82.

31 Pacheco GE, Garcia-Onrubia L, Garcia-Alvarez C, et al. A retrospective review of conjunctival melanoma: presentation, treatment and evolution. Arch Soc Esp Oftalmol 2019;94:218-24.

32 Savar A, Esmaeli B, Ho H, et al. Conjunctival melanoma: local-regional control rates, and impact of high-risk histopathologic features. J Cutan Pathol 2011;38:18-24.

33 Triay E, Bergman L, Nilsson B, et al. Time trends in the incidence of conjunctival melanoma in Sweden. Br J Ophthalmol 2009:93:1524-8.

34 Shields CL. Conjunctival melanoma: risk factors for recurrence, exenteration, metastasis, and death in 150 consecutive patients. Trans Am Ophthalmol Soc 2000;98:471-92

35 Kaliki S, Vasanthapuram VH, Mishra DK. Conjunctival melanoma in Asian Indians: a study of 42 patients. Semin Ophthalmol 2019:34:182-7.

36 Fasina 0, Oluwasola OA. Conjunctival melanoma in Southwestern Nigeria: a case series and review of literature. Int Ophthalmol 2018:38:1747-52.

37 Taban M, Traboulsi El. Malignant melanoma of the conjunctiva in children: a review of the international literature 1965-2006. J Pediatr Ophthalmo/ Strabismus 2007;44:277-82

38 Kaštelan S, Gverović Antunica A, Beketić Orešković L, et al. Conjunctival melanoma epidemiological trends and features. Pathol Oncol Res 2018;24:787-96.

39 Ghazawi FM, Darwich $\mathrm{R}$, Le $\mathrm{M}$, et al. Incidence trends of conjunctival malignant melanoma in Canada. Br J Ophthalmol 2019;103:1872-6.

40 Yousef YA, Finger PT. Squamous carcinoma and dysplasia of the conjunctiva and cornea: an analysis of 101 cases. Ophthalmology 2012;119:233-40.

41 Sheng X, Li S, Chi Z, et al. Prognostic factors for conjunctival melanoma: a study in ethnic Chinese patients. Br J Ophthalmol 2015:99:990-6.

42 Esmaeli B, Wang $X$, Youssef $A$, et al. Patterns of regional and distant metastasis in patients with conjunctival melanoma: experience at a cancer center over four decades. Ophthalmology 2001;108:2101-5.

43 Shields CL, Markowitz JS, Belinsky I, et al. Conjunctival melanoma: outcomes based on tumor origin in 382 consecutive cases. Ophthalmology 2011;118:389-95.

44 Finger PT, Pavlick AC. Checkpoint inhibition immunotherapy for advanced local and systemic conjunctival melanoma: a clinical case series. J Immunother Cancer 2019;7:83-90.

45 Kenawy N, Kalirai H, Sacco JJ, et al. Conjunctival melanoma copy number alterations and correlation with mutation status, tumor features, and clinical outcome. Pigment Cell Melanoma Res 2019;32:564-75 